\title{
Redes intelectuales y redes textuales: las revistas del Reformismo Universitario
}

\author{
Liliana Weinberg*
}

Recibido el 18 de julio de 2019; aceptado el 15 de noviembre de 2019

\section{RESUMEN}

Una auténtica constelación de revistas acompañó los procesos de génesis, consolidación, expansión y complejización del discurso del movimiento del reformismo universitario que tuvo su epicentro en Córdoba, Argentina, en 1918 y pronto se extendió a otros ámbitos del continente, en un fenómeno que puso en evidencia la fuerte imbricación y la poderosa retroalimentación que pueden existir en determinados períodos históricos no sólo entre prácticas y discursos sino también entre redes intelectuales y redes textuales. Se revisan algunos de los alcances y las grandes líneas del movimiento reformista y se enfatiza el papel que tocó cumplir en él a las revistas. Si ya en su momento autores como José Ingenieros advertían el peso específico de las publicaciones periódicas de la hora al referirse a las "cien revistas" del reformismo, en nuestros días toda una nueva generación de estudiosos y centros de investigación dedicados a la recuperación documental, al análisis acucioso, la difusión y reinterpretación del reformismo universitario de 1918 desde la mirada de la historia intelectual, el estudio de prácticas y rituales de sociabilidad y el tejido de redes intelectuales ha permitido enriquecer sustantivamente el estudio y la comprensión del papel que desempeñaron las revistas para la historia cultural y la producción intelectual en y sobre América Latina. En el presente artículo se pasa revista a algunos de estos aportes y se

* Centro de Investigaciones sobre América Latina y el Caribe, Universidad Nacional Autónoma de México, (UNAM), México. Correo electrónico: weinberg@unam.mx. ORCID: 0000-0002-7006-7812. 
proponen para la reflexión algunos temas como la necesidad de estudiar a fondo y complejizar la relación entre redes intelectuales y redes textuales, prácticas y discursos, formaciones e instituciones, producción intelectual y discurso social, e incluso se sugiere que, desde la perspectiva latinoamericana, se hace necesario pensar en nuevas instancias articuladoras entre estas distintas duplas.

Palabras clave: Revistas, redes intelectuales, redes textuales, Reforma Universitaria, latinoamericanismo.

\title{
Intellectual networks and textual networks: the journals from the University Reform Movement
}

\begin{abstract}
During the University Reform Movement which started in Córdoba, Argentina, in 1918, a constellation of journals was part of the process of genesis, consolidation, expansion, and complexification of its discourse and soon expanded into other areas of the continent. The phenomenon evidenced the strong imbrication and powerful feedback that can exist in a certain historical period, not only between practices and discourses, but also between intellectual networks and textual networks. This research presents an analysis of the scope and the overarching themes of the University Reform Movement, underscoring the role played by journals. Authors like José Ingenieros foresaw the specific importance that periodical publications had when he wrote about "the hundred journals" of Reform. Today there is a new generation of intellectuals and research centers dedicated to document recovery, discourse analysis, distribution, and reinterpretation of the 1918 University Reform. The approaches of intellectual history, the study of sociability practices and rituals, and the weaving of intellectual networks have allowed us to enrich the study and comprehension of journals substantially, as well as the central role they played in cultural history and intellectual production in and about Latin America. This article will discuss some of these contributions and will bring into consideration the need to make an in-depth study and problematize the relationship between intellectual networks and textual networks, as well as practices and discourses, formations and institutions, intellectual production, and social discourse. The article explores how, from the Latin American perspective, it has become necessary to think of new articulating instances between these elements.
\end{abstract}


Keywords: Journals, intellectual networks, textual networks, University Reform Movement, Latin Americanism.

A la memoria de mi padre, Gregorio Weinberg, al cumplirse cien años de su nacimiento, por su renovadora mirada sobre la Reforma Universitaria.

\section{"LOS GRITOS COBRAN LA DIGNIDAD DE LAS IDEAS"}

$\Lambda$ dmirable es la enorme cantidad y variedad de textos ligados al movimiento de la Reforma Universitaria que se declaró en la ciudad argentina de Córdoba en 1918, cuyo ideario tuvo amplia recepción y rápida expansión por distintas ciudades de América Latina. ${ }^{1}$ El reformismo hizo de la producción escrita una clave de su validación simbólica: el quehacer de las letras se imbrica con el quehacer de las ideas, la expansión de los textos es a la vez trasunto de la expansión de las propuestas. Sus protagonistas fueron, en muchos casos, actores y autores que hicieron de la posibilidad de consignar los hechos y reflexionar sobre su sentido una forma de construir su propio perfil intelectual y contribuir a pensar el movimiento mismo. Es así como la circulación de las ideas se vio retroalimentada por la eclosión de una amplia gama de formas de la prosa no ficcional: manifiestos, discursos, ensayos, artículos en periódicos, boletines y revistas son sólo algunas muestras de ello. Por otra parte, el gran caudal de documentos y publicaciones del reformismo que se han ido rescatando a lo largo de los años, y muy particularmente las revistas, constituyen un archivo invaluable para comprender los modos y mecanismos de esta tan notable multiplicación y articulación entre prácticas y discursos que hizo que muy pronto Deodoro Roca, uno de los principales protagonistas del movimiento, llegara a afirmar que "los gritos cobran la dignidad de las ideas”. ${ }^{2}$

1 La autora agradece a la DGAPA, UNAM, su apoyo para la realización de una estancia sabática en La Plata y Buenos Aires entre fines de agosto y principios de octubre de 2018, así como reconoce también el hospitalario y generoso apoyo recibido por parte de colegas e instituciones de esas dos ciudades argentinas. La visita a los acervos de la Biblioteca Pública de la Universidad Nacional de La Plata, el Museo Azzarini, la Universidad Popular Alejandro Korn, la Biblioteca Nacional de la República de Argentina y el CeDinCi me permitió consultar de primera mano valiosos materiales del reformismo, y particularmente un buen número de periódicos, boletines y revistas de la época.

2 "La nueva generación americana”, discurso de clausura de Deodoro Roca en el Primer Congreso Nacional de Estudiantes Universitarios reunido en la ciudad de Córdoba, Argentina, el 31 de julio de 1918, p. 50. 
Pensemos en que a través de distintos soportes — del telegrama al manifiesto, del discurso al artículo-, es posible hacer un seguimiento del modo en que ideas y sentimientos migran, se recombinan, se reinterpretan, se representan a través de la letra escrita: los actores se vuelven autores y los textos anudan y vuelven a tejer infinitas hiladas procedentes de incontables prácticas y discursos, condensando y enriqueciendo un imaginario que a su vez se retroalimenta a partir de ellos. Desde luego que estos textos no sólo pueden desembocar en síntesis armónicas de elementos, o traducir mansamente sentimientos individuales, grupales, generacionales, epocales, sino que también representan simbólicamente tensiones, contradicciones, tironeos ideológicos, tomas de posición y distancia, rupturas, y de este modo reabren el diálogo y dan lugar a nuevas líneas de interpretación y debate.

Considero que para la comprensión de todos estos textos militantes y "reflexionantes" que componen el gran archivo simbólico del reformismo universitario, así como para hacer un seguimiento del itinerario de estos sentimientos de época y de los "conceptos viajeros" (tomo esta acertada expresión de Jorge Myers), es necesario atender no sólo a su decir sino a su querer decir, ya que con ello es posible interpretar el modo en que lograron incidir en la construcción de un discurso sobre lo público. Para estudiar un texto no sólo es necesario atender a su descripción como unidad de sentido, sino también a su "intención significativa", ${ }^{3}$ y ello nos conduce a tomar en cuenta su inscripción en ese complejo entramado histórico en que intervienen desde luego innumerables componentes políticos, sociales, simbólicos etcétera. En el caso de América Latina, este carácter responsivo y responsable de la asunción de la palabra tiene grandes consecuencias para la articulación del discurso sobre la cosa pública.

De modo que para entender ese querer decir es necesario no sólo atenerse a las ideas y las palabras sino al ámbito en que se presentan, a las prácticas de sociabilidad y a las manifestaciones políticas de las que provienen y en que se inscriben o las formas de diálogo, polémica y militancia que alimentan. Estos textos no pueden leerse sólo de manera aislada: lo hacen también en su vínculo con las otras formas de la prosa de ideas con que entran en relación, así como con las redes de textos y familias de sentido en que se inscriben y a las que a su vez representan simbólicamente.

Me refiero a "redes textuales" en por lo menos dos sentidos. Por una parte, al modo en que los textos son capaces de representar y recrear simbólicamente la existencia de redes de debate y discusión a la vez que de ofrecer a las "redes intelectuales" nuevos elementos de confluencia o tensión. Por

\footnotetext{
${ }^{3}$ Término empleado por Maurice Merleau-Ponty en “Sur la phénoménologie du langage”, p. 84.
} 
otra parte, en cuanto los textos son un elemento fundamental para la autopercepción del quehacer intelectual y la constitución de los actores como autores.

Por lo demás, acercarnos al reformismo no sólo a través de los textos unitarios, sino también de ese amplio acervo integrado por las publicaciones periódicas a él ligadas nos hace comprender la existencia de una amplia gama de textos en diversos formatos y soportes, los que van tramando complejas “redes textuales" profundamente imbricadas con las "redes intelectuales" y de militancia política que nutren al movimiento.

Los diferentes componentes del ideario reformista argentino serán retomados muy tempranamente por distintas publicaciones latinoamericanas y encontrarán expansión continental gracias a revistas como Amauta y Repertorio Americano, y se retroalimentarán a su vez con las ideas, inquietudes y debates propios de los distintos rincones de América que le dieron recepción, particularmente con el sentido de compromiso social y de misión que implicaba para esos nuevos actores fundamentales: los estudiantes. Por otra parte, al entrar en diálogo con los distintos ambientes y climas intelectuales, muchas de las principales propuestas del reformismo se fueron enriqueciendo y complejizando. Tal es, por ejemplo, el caso del concepto de 'autonomía', que todos tendemos a asociar con la Reforma, que en sus primeros momentos comienza siendo un llamado al co-gobierno y la libertad de cátedra (aunque protagonistas del reformismo como Emilio Biagosch tenían ya desde muy temprano una muy aguda concepción de ella), conforme transcurra el tiempo y se reinterprete en la militancia y en el papel se convertirá en una palabra de pase fundamental cargada de nuevos sentidos. La exigencia de una renovación en los contenidos de la educación, el imperativo de abrir la discusión y la difusión de las ideas a distintos sectores de la sociedad o la necesidad de enriquecer con nuevas perspectivas la formación meramente profesionalizante, está también en muchos autores.

¿Qué hace que una revista pueda ser considerada "reformista”? ¿Cuáles fueron las grandes líneas de las publicaciones ligadas a este movimiento? $¿$ Es posible trazar dentro de este amplio agrupamiento, conjuntos y subconjuntos temáticos e ideológicos? ¿Qué criterios clasificatorios se siguieron para ello? Se trata de un debate que deberá ser retomado conforme avance el relevamiento y estudio de las fuentes, y al que queremos contribuir con algunas nuevas preguntas: $\dot{i}$ Es posible atender prioritariamente a los programas explícitos o a las respectivas declaraciones de principios o bien es preciso seguir las grandes líneas y tensiones ideológicas que se van desenvolviendo a través de los sucesivos números? ¿Es necesario y suficiente atenerse a los nombres de sus fundadores y seguir con atención los listados de colaboradores, la interrelación que establecen en el ámbito de la revista y sus respectivas trayectorias, o es también relevante la obtención de datos 
provenientes de los suscriptores y patrocinadores para comprender las grandes líneas de consenso y discusión que las caracterizaron?

Se trata de una investigación abierta y en marcha, a la que mucho están contribuyendo en los últimos años los aportes de distintos estudiosos: la celebración de los cien años de la Reforma constituyó un momento propicio para que se diera toda una nueva generación de investigaciones, rescates documentales, valoraciones. Conforme se avanza en la admirable y generosa tarea de recuperación, registro y reproducción de los distintos títulos, se hace posible establecer interrelaciones, recurrencias, diferencias, y esbozar diversas propuestas de lectura.

Lo cierto es que nos encontramos ante un valioso universo de publicaciones que permitieron articular hechos e ideas, ver la relación entre autores y actores, inscribir el movimiento en el largo plazo de la historia y el espacio americano, representar y traducir simbólicamente los diálogos, polémicas, acuerdos, confrontaciones que hoy nos permiten contextualizar y comprender mejor un ideario complejo y abierto a nuevas claves interpretativas. En el interior mismo de las distintas colaboraciones puede advertirse la formación de familias temáticas e ideológicas que deberán ser confrontadas con otros elementos y datos procedentes de los distintos números, para enriquecer la concepción de diálogo y relacionalidad. En el espacio de las revistas confluyen de manera privilegiada y se representan simbólicamente las posibilidades de encuentro entre los textos y el mundo.

\section{REDES INTELECTUALES Y REDES TEXTUALES}

El estudio del amplio corpus de publicaciones ligado al Reformismo Universitario de 1918 constituye un mirador privilegiado para observar ese movimiento y poner en relación fuerte "redes intelectuales" y "redes textuales": dos sistemas vivos y activos que en muchos casos pueden examinarse en permanente retroalimentación y tensión, y que a su vez contribuyen mutua y solidariamente al tejido, ampliación, convergencia, divergencia, consolidación, ramificación, replanteamiento de sistemas, de ideas y valores, posturas y programas de acción, conceptos y símbolos, diagnósticos puntuales e imaginarios expansivos. Un caso singular y un ejemplo preclaro de esto es el modo en que las redes de publicaciones, y particularmente para el caso que nos ocupa, de revistas, contribuyeron a gestar, configurar y multiplicar las redes del reformismo universitario.

En nuestros días existe toda una nueva generación de estudios críticos y valoraciones sobre la Reforma de 1918, que permiten comprobar cómo los componentes nucleares de su ideario se irán reexaminando críticamente, enriqueciendo, recombinando, madurando, en una permanente retroalimentación 
entre los impresos, los viajes, las cartas, los congresos, las prácticas de sociabilidad, la oratoria y los rituales del reformismo (discursos, mítines, himnos) que acompañan a los principales voceros del movimiento reformista-americanista como Palacios, Haya de la Torre, Vasconcelos, y a la vez servirán como canales de transmisión de ideas, pero también como laboratorios de ideas. Valioso es el surgimiento de tesis y estudios críticos que renovaron las interpretaciones tradicionales al análisis el tratamiento de las revistas, como es el caso de los trabajos de Natalia Bustelo. Valiosos son también los trabajos integrados en colecciones como la que lleva por título "Dimensiones del Reformismo Universitario", publicada por la Facultad de Humanidades y Artes de la Universidad Nacional de Rosario, Argentina, y de la cual ya han aparecido seis títulos. Admirable es además el trabajo de recuperación y estudio de revistas del reformismo que ha llevado a cabo el CeDInCI. ${ }^{4}$

Por otra parte, si bien el movimiento de la Reforma propiamente dicho se detona en Córdoba en 1918, muchas de las ideas, estructuras de sentimiento, propuestas, prácticas y discursos provienen de años anteriores y atraviesan interesantes procesos de reconfiguración en título y contenido para rearticularse y dar lugar a nuevas publicaciones cuando se expanda el movimiento estudiantil por distintos rincones de América. De allí que atender al desenvolvimiento de esas redes nos permita, coincidiendo con las palabras de Martín Bergel, seguir "los avatares del movimiento en su discurrir en el tiempo, y sobre todo en el espacio". ${ }^{5}$ En efecto, mucho deben la espacialización de la historia y la politización del espacio en esos años a los modos de edición, circulación e intercambio de publicaciones, a los que se suman diversas manifestaciones y prácticas de sociabilidad intelectual, que se refuerzan y a la vez contribuyen a fortalecer el poder expansivo y multiplicador de la circulación de ideas que permite la llegada de impresos, boletines, revistas, diarios, libros, a distintos rincones de América.

Otro tanto sucede con las revistas, ya que están abiertas a las formas de sociabilidad e intercambio de ideas en que se inscriben, a la vez que configuran laboratorios, escenarios, donde las ideas, los símbolos, las estructuras de sentimiento se retoman, se asientan, se recombinan, se reconfiguran. Existe, en palabras de Martín Bergel, un "excedente simbólico" que las revistas contribuyen a retomar y reinterpretar. En el ideario del reformismo también se manifiestan tensiones muy fuertes.

4 Véase “AméricaLee, Portal de Revistas Latinoamericanas del Siglo XX del Centro de Documentación e Investigación de la Cultura de Izquierdas (CeDInCI)”, http://americalee.cedinci.org/.

5 Bergel (coord.), Los viajes latinoamericanos de la Reforma Universitaria, p. 8. 
Para sólo tomar algunos de los principales ejemplos de ello, pensemos en las fuerzas "centrípetas" que buscan concentrar las discusiones en los problemas de la propia universidad y responder a las demandas meramente institucionales, localizadas e inmediatas, y las fuerzas "centrífugas" que buscan abrir la discusión a la sociedad y dar a las ideas una expansión nacional y continental. Por lo demás, el propio "americanismo" de cuño arielista y modernista de la primera hora se irá complejizando y reconfigurando, por una parte, ante las demandas de convertirse en un "americanismo diferencial" y por otra parte, ante las demandas "internacionalistas" que buscan la solidaridad de los pueblos, hasta tocarse con el antiimperialismo ${ }^{6}$ y en muchos casos, al entretejerse con claves estéticas procedentes del realismo, el realismo social y las vanguardias, en complejas vertientes. Pensemos también en el contraste entre aquellas publicaciones que optaron por asumir una declarada postura de compromiso, propaganda y adhesión a distintos movimientos políticos y sociales y aquéllas que buscaron deslindarse de las demandas ideológicas del momento para orientarse a otros debates y discusiones de corte literario o filosófico: todo ello conducía a su vez al tejido de nuevas redes.

En un artículo fundamental para el tema que nos ocupa, dice Horacio Tarcus lo siguiente:

Una verdadera red de intercambios unía en los años veinte todos los puntos de América Latina, en un grado que sorprende incluso hoy, en los tiempos de internet. Circulación a través de las revistas (por intercambios entre ellas para su venta, por los canjes de avisos, por los comentarios recíprocos), y circulación de las personas (a través de la nutrida correspondencia, o de los viajes para dictar conferencias, para asistir a congresos políticos, los exilios, etc.). Son los años de la proyección latinoamericana de la Reforma Universitaria, de la Unión Latinoamericana, del primer APRA, de la internacional comunista y de los movimientos literarios de vanguardia: todos esos procesos van a propiciar la circulación de ideas, de revistas, de figuras. Dentro del abigarrado cuadro de vínculos políticos y culturales que se establecen entre distintos puntos de Latinoamérica, a lo largo de los años veinte, sobresale la encrucijada que resulta del cruce de tres líneas significativas de pensamiento y acción: el americanismo, el antiimperialismo y el socialismo. Cruce de tres líneas que remiten a las tres figuras claves de la época: el peruano José Carlos Mariátegui, el americano Waldo Frank y el argentino Samuel Glusberg. Un seguimiento de las revistas que animaron, de los textos que unos escribían acerca de los otros y de la correspondencia mantenida entre ellos, permitirá echar luz sobre algu-

6 Para este tema véase Pita y Marichal, Pensar el antiimperialismo, ensayos de historia intelectual, México: El Colegio de México-Universidad de Colima, 2012. 
nas zonas poco conocidas del campo intelectual y político, tanto en Argentina como en Latinoamérica. ${ }^{7}$

De allí que podamos suscribir, con Adriana Petra, ${ }^{8}$ la idea de que la letra impresa alcanza en ciertos períodos una particular "centralidad". Si esta estudiosa se refirió de manera notable a la Internacional Comunista como una "Internacional de Papel”, otro tanto es posible considerar respecto del movimiento de la Reforma Universitaria, en el cual el impreso alcanzó una función central (desde los manifiestos y proclamas hasta los discursos y los libros). Y particularmente han sido las revistas lugares donde ese punto de articulación entre prácticas y discursos resultó fundamental, como lo ha sido el tránsito de umbral entre texto y contexto.

Se trata de un fenómeno que puso en evidencia la fuerte imbricación y poderosa retroalimentación entre prácticas y discursos que pueden quedar representados en determinados períodos históricos. Tal el caso de los “vectores de ideas" que atraviesan distintos soportes y se integran a distintas familias textuales que a su vez contribuyen a reinterpretarlos y reconfigurarlos. Y tal es también el caso del alto dinamismo de los artículos que se integran en las publicaciones periódicas, así como también el modo en que estas últimas pueden traducir y confirmar la existencia de redes que vinculan y sustentan el quehacer de los intelectuales y los textos que lo fortalecen, al tiempo que plantear diferencias y abrir nuevos rumbos ideológicos.

Es así como el estudio de prácticas y rituales de sociabilidad y del tejido de redes intelectuales del reformismo ha permitido enriquecer sustantivamente la comprensión del papel que desempeñaron las revistas para la historia cultural y la producción intelectual en y sobre América Latina. El estudio de las revistas contribuye a hacer un seguimiento histórico, geográfico, ideológico del reformismo y los movimientos estudiantiles y políticos a él ligados: pensemos sin ir más lejos en los fenómenos de patrocinio, circulación, suscripción, recepción, distribución de las publicaciones periódicas. Pensemos también en los anuncios de editoriales y librerías, en los sistemas de intercambio y reproducción de textos, en la inserción de cartas y tomas de posición de quienes en muchos casos eran a la vez lectores, autores y protagonistas de los acontecimientos.

Si bien la letra impresa nos ofrece un mirador privilegiado para analizar los distintos canales de transmisión de las ideas, no debemos olvidar que éstos no se circunscriben sólo a las publicaciones, sino que existen innume-

7 Tarcus, "Revistas, intelectuales y formaciones culturales izquierdistas en la Argentina de los veinte”, p. 760.

8 Petra, Intelectuales y Cultura Comunista. Itinerarios, problemas y debates en la Argentina de posguerra. 
rables formas vivas y situadas de encuentro y socialización ligadas a la militancia política y la sociabilidad intelectual, desde los mítines, protestas, huelgas, asambleas y congresos estudiantiles hasta los cursos y conferencias, universidades populares, reuniones de debate, donde se gestan y recombinan las preocupaciones de época.

Pensemos además en la originalidad de las publicaciones del Reformismo, que irán definiendo su perfil en una época de eclosión de publicaciones de amplio espectro: diarios que difunden noticias de alcance nacional, por ejemplo, pero también muchas publicaciones ligadas a los movimientos obreros, socialistas, anarquistas. Subrayemos la especificidad del proceso que representa el surgimiento en el espacio público argentino y latinoamericano de todo un sector particular de revistas ligadas a los movimientos estudiantiles, que deberán a su vez rearticularse con las publicaciones científicas, políticas, culturales de ese momento: una articulación que vuelve aún más compleja la posibilidad de identificar revistas reformistas, por decirlo así, "en estado puro". Los actores del Reformismo pasaron del grito a la idea: de la denuncia del instante a la reflexión a largo plazo. Las revistas del Reformismo cumplen también a cabalidad los rasgos marcados por Julliard para las publicaciones de principios de siglo Xx. Primero, se trata de espacios de innovación, en la mayoría de los casos fundados por jóvenes: "una revista es siempre más o menos, en sus comienzos, un hecho de generación, que reúne hombres, y más raramente mujeres, alrededor de una emoción, de un acontecimiento, de una idea que ella se esfuerza por transformar en experiencia". Segundo, constituyen "un antídoto indispensable" para contrarrestar los efectos de la "pesada maquinaria" de las distintas organizaciones políticas o sindicales y las consecuentes amenazas de cristalización ideológica, en cuanto representan "un espacio de libertad, un lugar donde la importancia de una idea no se mide en nombre de las directivas que puedan nuclearse alrededor de ella sino por su valor intrínseco". Tercero, las revistas son también "lugares de sociabilidad" donde "se afirma una identidad de grupo", donde "se dibuja el juego del 'nosotros' y del 'ellos””: "en los márgenes de las organizaciones, ellas permiten a las corrientes de pensamiento tomar conciencia de sí mismas y expresarse". En fin, "las revistas son lugares de moralidad: se trata de dar un sentido más puro a las palabras de la tribu, en el caso de las revistas comprometidas, o de manera más general, de hacer una revolución mental”. De allí la importancia de la intensidad de su mensaje. ${ }^{9}$

La Reforma Universitaria es un movimiento que desde muy temprano concitó entre sus protagonistas y simpatizantes un enorme interés por ge- 
nerar publicaciones, recopilar fuentes, proponer lecturas, establecer nuevas tradiciones de pensamiento, propiciar reflexiones y promover valoraciones que permitieran inscribir el corto plazo y la situacionalidad de los acontecimientos en el tiempo largo de la historia y la geografía americanas, así como examinar hechos, actores e ideas con el afán de ponerlos en perspectiva. Sin ir más lejos, pensemos que las revistas del reformismo, los ensayos escritos por sus protagonistas, los libros de largo aliento y las antologías que reunían documentos y valoraciones aparecieron muy tempranamente, casi de manera simultánea con los acontecimientos, y fueron indicando incluso líneas interpretativas del reformismo. Tal es el caso de libros de la magnitud de la compilación de Gabriel del Mazo, publicada a principios de la década de los cuarenta, que fueron ofreciendo datos clave de la autopercepción intelectual del movimiento. Esta misma impresión se confirma al revisar estudios señeros como los de Alberto Ciria y Horacio Sanguinetti (1968), de Dardo Cúneo o Juan Carlos Portantiero (ambos publicados en 1978), y que abrieron nuevas perspectivas para la comprensión del fenómeno reformista.

Por fin, mencionemos que si bien en nuestro medio ya se encuentran muy avanzados los estudios y propuestas teóricas centrados en las "redes intelectuales", no puede decirse lo mismo respecto de la noción de "redes textuales", que apenas en años recientes comienza a llamar la atención de los estudiosos: citemos entre ellos a Joan Miguel Vert Pericás y otros autores, que nos ofrecen un panorama de los distintos sentidos y tratamientos a que ha dado lugar este concepto: se trata de una concepción relacional, inspirada en el modelo de análisis de las redes sociales, que busca llevar a cabo el análisis de textos y discursos con especial énfasis en el análisis reticular del discurso. Por nuestra parte, lo que deseamos enfatizar es el vínculo y la correspondencia que puede encontrarse entre redes intelectuales y redes textuales, particularmente para casos como el del reformismo, que hizo de la palabra impresa una de las formas más fuertes para reforzar la prédica política e ideológica y las redes de militancia y reflexión que éstas implicaron. ${ }^{10}$

10 Estos estudiosos pasan revista a "las diferentes propuestas que dentro del ámbito de la sociología (o cercanos) toman elementos de o se han inspirado en el Análisis de Redes Sociales para realizar el análisis de textos y/o discursos. A pesar de que la concepción relacionista tiene ya una cierta tradición en el análisis del discurso, no ha sido más que a partir de la década de los ochenta que se han desarrollado propuestas que, con mayor o menor intensidad, aplican la idea y el instrumental de redes sociales al análisis de textos”. Afirman que "Sólo algunos procedimientos llegan a utilizar la aproximación reticular como forma de preservar la articulación, y con ello, la estructura semántica y sintáctica del texto”. Véase Lozares Colina, Verd Pericás, Martí Olivé y López Roldán, "Relaciones, redes y discurso: revisión y propuesta en torno al análisis reticular de datos textuales”. 


\section{“Cien Revistas”}

En 1924, al hacer un balance del movimiento reformista a través de su ensayo "La Reforma en América Latina", uno de los principales mentores y protagonistas del movimiento, el filósofo argentino José Ingenieros, escribe:

El generoso movimiento de renovación liberal iniciado en 1918 por los estudiantes de Córdoba, va adquiriendo en nuestra América los caracteres de un acontecimiento histórico de magnitud continental. Sus ecos inmediatos en Buenos Aires y México, en Santiago de Chile y La Habana, en Lima y Montevideo, han despertado en todos los demás países un vivo deseo de propiciar análogas conquistas. En cien revistas estudiantiles se reclama la reforma de los estudios en sentido científico y moderno, se afirma el derecho de los estudiantes a tener representación en los cuerpos directivos de la enseñanza, se proclama la necesidad de dar carácter extensivo a las universidades, y se expresa, en fin, que la nueva generación comparte los ideales de reforma política y económica que tiendan a ampliar en sus pueblos la justicia social. ${ }^{11}$

En efecto, la proliferación de revistas ligadas al movimiento reformista que hizo eclosión en 1918 llevó a Ingenieros a referirse a ese alto número de publicaciones, que tuvo no sólo un peso cuantitativo sino desde luego cualitativo en la génesis, consolidación, difusión, del ideario estudiantil. Éste, a su vez, permeó formatos y se multiplicó en otras grandes publicaciones de carácter latinoamericanista.

Martín Bergel vincula esta posibilidad de difusión del ideario reformista con otras dos prácticas características de la época: el intercambio epistolar y los viajes, y observa cómo los alcances del clima americanista de los años veinte pueden rastrearse en otras importantes revistas de distinta gama ideológica:

Las cien revistas reformistas mencionadas en la cita resultan un número apenas exagerado (como bien lo sabía Ingenieros, que recibía una abundante correspondencia de pequeñas ciudades del interior de varios países del continente). Pero si agregamos a esa referencia cuantitativa otra de carácter cualitativo, podemos mencionar que incluso la revista argentina Sur, fundada por Victoria Ocampo en 1931, y por décadas una de las principales publicaciones culturales del continente -acusada repetidamente en el curso de su larga trayectoria de estar ceñida a un liberalismo europeísta sin fisuras-, se verá atravesada por el clima americanista de la década del 20. Así, quien revi- 
se sobre todo sus primeros años de existencia podrá advertir que una inflexión continentalista no era ajena a sus páginas. ${ }^{12}$

Coincido con Bergel en cuanto a la importancia de esas grandes revistas, tan vinculadas al latinoamericanismo que desplegaron los jóvenes reformistas: la peruana Amauta, de José Carlos Mariátegui (1926-1930), que dio además expresión al vanguardismo político y estético de la hora, que alimentó el debate reformista que se expandía por distintas zonas de América Latina y fue así capaz de movilizar redes americanas que a su vez evidenciaron que "la perspectiva continental estuvo en el centro de su apuesta políticocultural” y la costarricense Repertorio Americano, de Joaquín García Monge, surgida en 1919 dentro de la atmósfera continentalista de la hora, y que dio muestras de una clara voluntad latinoamericanista.

En cuanto a los modos de multiplicación de ese imaginario, anota el propio Bergel:

Ese nutrido campo de revistas culturales y políticas impactó de diversos modos en el imaginario continentalista impulsado por la generación reformista. En su nivel más obvio, tanto los autores de diversos países del continente que escribían en esas publicaciones como los contenidos explícitos de los artículos, se vinculaban directamente con la prédica americanista de los reformistas. Varias de esas revistas tenían secciones dedicadas especialmente a cuestiones universitarias o ligadas a una perspectiva continental.

En el mismo texto, Bergel cita el ejemplo de la revista platense Sagitario, dirigida por Carlos Américo Amaya, Julio V. González y Carlos Sánchez Viamonte, de clara orientación reformista, que contó entre sus colaboradores a los peruanos Mariátegui, Haya de la Torre, Antenor Orrego y Eudocio Ravines, y al reformista uruguayo Carlos Quijano, impulsor a su vez de la revista Ariel de Montevideo. Además de los artículos propiamente dichos, Sagitario incluía noticias, comunicaciones, secciones explícitamente dedicadas a estos temas ("Universitarias” o “Amistad Americana”). A la vez, la revista se hacía eco de expresiones provenientes de distintas partes de América Latina, anuncios y menciones de libros, editoriales o librerías de nuestro continente. De este modo, las propias marcas materiales, la inclusión de autores y noticias provenientes de otras naciones americanas y los planes redes de dis-

12 Bergel, “América Latina, pero desde abajo: prácticas y representaciones intelectuales de un ciclo histórico latinoamericanista, 1898-1936”, https://scielo.conicyt.cl/scielo.php?script= sci_arttext\&pid=S0719-12432012000100001\&lng=es\&nrm=iso, [consultado el 4 de julio de 2019]. 
tribución eran señales que indicaban la inscripción de las mismas en "la trama trasnacional que las hacía posibles". Finalmente, si esos signos señalan la matriz americana que contribuía a vincular la producción y difusión de este tipo de artefacto cultural, también el momento de su distribución requería tanto como fomentaba redes que iban más allá de las ciudades y países de su factura original.

Las “cien revistas” tuvieron además un importante papel en la configuración del perfil intelectual de los reformistas. Procedentes de sectores medios de creciente presencia, estos nuevos actores fueron reforzando su función y su lugar en los debates ideológicos a través de sus publicaciones. Identificándose a sí mismos como estudiantes, como jóvenes, como profesionales renovadores y críticos, es bueno recordar que constituyeron la "masa crítica" de universitarios que fue capaz de detonar el movimiento surgido en la ciudad de Córdoba en 1918 y que pronto se expandió a distintas ciudades de Argentina y América Latina. Dicho movimiento fue así apoyado predominantemente por jóvenes estudiantes, egresados y jóvenes profesionales provenientes de sectores medios urbanos emergentes, que exigían la renovación de la vida universitaria y de la función de la universidad en la sociedad y en América Latina. Como anota Carlos Tünnerman, se trató del "primer cuestionamiento" en profundidad de la universidad tradicional (que continuaba siendo todavía en muchos lugares un "virreinato del espíritu"), en un año que "señala, según algunos sociólogos, el momento del ingreso de América Latina en el siglo XX". ${ }^{13}$

El Reformismo abarcó una amplia gama de reclamos, que fueron desde las primeras exigencias estudiantiles o "gremiales" concretas hasta cuestiones que reflejaban las preocupaciones por su época y su sociedad, por el vínculo con otros sectores y con otras regiones de Argentina y América Latina. El movimiento reformista buscaba lograr una mayor presencia estudiantil en el gobierno y en la toma de decisiones académicas y administrativas de la universidad, así como promover una mayor presencia de estos jóvenes en la vida social y la apertura de la institución a las demandas de su

13 Me refiero al texto clásico de Carlos Tünnermann Bernheim, "La reforma universitaria de Córdoba”, p. 104. Recupera también el autor ideas centrales de Augusto Salazar Bondy: "Lo primero que hay que tener presente es que ella respondió a un proceso muy amplio e intenso de agitación social. Cambios en la correlación internacional de las fuerzas políticoeconómicas, derivados de la guerra y cambios internos, vinculados con la expansión del capitalismo en Latinoamérica y la emergencia de una clase media que había aumentado considerablemente su número y su participación activa en el proceso social así como una notoria inquietud en el proletariado que ya se hacía sentir en los principales centros urbanos, determinaron la presencia de un clima propicio a las más hondas transformaciones” (pp. 104105). 
momento. De allí la exigencia de que se diera publicidad y transparencia a los actos de gobierno universitario y la propuesta de organizar asociaciones representativas para la defensa de las reivindicaciones estudiantiles. En una nueva concepción del estudiantado, el magisterio y la vida profesional, se propiciaron reformas en la propia vida de las instituciones, como la necesidad de una mayor presencia estudiantil y cogobierno, designación de docentes a través de concursos de oposición transparentes, libertad de cátedra, asistencia libre, laicismo y gratuidad para democratizar las formas de acceso a la educación sin distinción de la extracción social del estudiante, apertura a nuevos contenidos acordes con la época y las demandas de la sociedad, etcétera. Resultado de todo ello serán las crecientes exigencias de participación estudiantil y autonomía universitaria, así como la apertura a una proyección continental del ideario reformista. ${ }^{14}$

El movimiento tradujo así una creciente toma de conciencia de los problemas nacionales e internacionales, un intento de participación política y articulación con otros sectores de la sociedad, y sobre todo, una creciente apertura latinoamericana y politización a nivel continental. Representó una puesta al día y una respuesta a los tiempos convulsos que se vivían tanto en el ámbito nacional como internacional, y que aspiraba sobre todo a alcanzar una articulación latinoamericanista y progresivamente antiimperialista, atenta a las exigencias de otros grupos sociales y pugnas políticas e ideológicas, con las que en algunos casos buscó comprometerse y de las que en otros casos buscó deslindarse.

En el contexto internacional, el reformismo comienza a gestarse cuando han estallado la Revolución Mexicana y la Revolución Rusa y se asiste a los avatares de la Primera Guerra mundial. En el contexto nacional argentino se viven los efectos sociales del reajuste económico ante las nuevas condiciones de la economía mundial, las consecuencias demográficas y sociales de los marcados procesos inmigratorios y migratorios, las nuevas exigencias de los sectores medios, que presionan por su inclusión en las decisiones políticas, un notable crecimiento urbano, la expansión de la alfabetización, fuerte politización, dinamización de las comunicaciones gracias a ferrocarriles, barcos y correo, crecimiento del sector terciario, profesional y de servicios, y comienzo de movimientos obreros, así como expansión del socialismo y el anarquismo. Se asistirá también a la victoria del radicalismo, que traduce precisamente la emergencia en el ámbito político de nuevos actores provenientes de las capas medias. Se multiplica, además, la demanda de publicaciones por parte de un acrecentado número de lectores y prácticas

14 Weinberg, “La reforma universitaria”, pp. 154 y siguientes. 
de lectura, con la circulación de un mayor número de periódicos y libros, y la multiplicación de bibliotecas públicas y populares. A todo ello agreguemos que asistimos a un momento en que surgen nuevas tendencias en el ámbito del arte y la literatura: al clima y la sensibilidad del modernismo y el posmodernismo pronto se sumarán las propuestas de las vanguardias.

Todas estas demandas se tradujeron en una amplia producción textual: la letra impresa desempeñó un papel clave en el movimiento. La Reforma se propaga desde Córdoba hasta otros puntos del continente y adquiere diversas características que, desde el comienzo, trascienden la universidad para proyectarse sobre la sociedad. En efecto, si bien comienza como un problema centrado en cuestiones y demandas "gremiales" concretas, de tal modo que incluso algunos sectores estudiantiles persistieron en su interés por limitar las exigencias a los aspectos institucionales propiamente dichos, muy pronto trasciende las reivindicaciones sectoriales para vincularse con las demandas de la comunidad, y en especial de algunos de sus grupos: clase media baja y estratos populares. Se deja de pensar en una educación de élite y se avanza en la posibilidad de ver en la educación superior una oportunidad de ascenso social y de reinserción en el mundo del trabajo (en una economía, por cierto, fuertemente terciarizada). Muchos de los temas y problemas que se abren entonces siguen siendo los de hoy: universidad de minorías o de mayorías, orientación profesionalizante o desarrollo de las ciencias y las humanidades, solidaridad de cuerpo o solidaridad social, alcance local o inscripción latinoamericana.

\section{DEL TELEGRAMA AL MANIFIESTO}

El "Manifiesto Liminar" de 1918 es ejemplo del modo en que los textos y discursos representan y reinterpretan prácticas y diálogos intelectuales; éste condensa el más temprano ideario reformista y fue a su vez ampliamente reproducido, difundido, leído y analizado en distintas ciudades de la Argentina y América Latina, generando un verdadero mapa del reformismo. Este manifiesto puede por su parte ser puesto en relación con otras formas textuales como telegramas, cartas, mensajes, artículos, discursos, proclamas o ensayos de interpretación del fenómeno estudiantil. En los distintos casos se dio una reconfiguración discursiva conforme a las exigencias retóricas propias de cada una de ellas.

El 18 de abril de 1918, el joven abogado cordobés Deodoro Roca envía un telegrama al maestro Ricardo Rojas, con las siguientes palabras:

Estamos iniciando la revolución que el país y su civilización esperaban. Córdoba es ya la ciudad más liberal del mundo. Al grito de Córdoba libre se está 
formando la nueva conciencia de una nueva Argentina, acabando de borrar para siempre el recuerdo de la contrarrevolución de mayo. Buenos Aires si quiere que esta hora tenga repercusión americana y no remate en sacrificio estéril la heroicidad de estos nobles muchachos debe dar su grito más fuerte. Estamos rompiendo aquí las cadenas con que se quiere encadenar la libertad de las generaciones actuales. Largo y fraternal abrazo. Deodoro Roca. ${ }^{15}$

Se trata de un valioso y poco conocido testimonio inaugural del movimiento de la Reforma Universitaria que había comenzado a gestarse desde meses atrás, y este anuncio del inicio de una revolución de declarado americanismo, juvenilismo y espíritu libertario, que, a la vez que apela al sentido de "heroicidad de estos nobles muchachos", afirma la voluntad de romper cadenas y promover el cambio a través de una revolución. Sorprende descubrir cómo, en un formato condensado y en una prosa urgente, se sintetizan y adelantan muchos de los términos de aquel documento que será conocido como "Manifiesto liminar" o Manifiesto de Córdoba del mismo 1918, y que tendrá amplia repercusión en toda América. En el caso del mensaje telegráfico, se trata de un anuncio perentorio, necesariamente breve, condensado, que obliga al emisor-firmante a medir, pesar y categorizar cada una de sus palabras, de tal modo que dice desde su mismo formato que se trata de un documento que anuncia, adelanta, plantea de manera esquemática y sintética algunos de los principales puntos del movimiento que habría de detonarse pocas semanas después. El telegrama constituye además un guiño de buenos entendedores a Ricardo Rojas, uno de los principales representantes del americanismo de la hora (aun cuando en ese primer momento Rojas mantuviera una postura distante respecto del reformismo). Alude también a una revolución social y estudiantil, al "grito de Córdoba”, a la ruptura con una precedente postura "antiliberal” y contrarrevolucionaria que traiciona el espíritu de Mayo en la universidad. Cada uno de estos hilos temáticos se irá tejiendo y volviendo a tejer para dar lugar a distintas texturas y mensajes ideológicos. El telegrama confirma el lugar principal que ocupaba ya Deodoro Roca en el movimiento y refuerza la presunción de que habría de tener un papel clave en la redacción del "Manifiesto”, aunque no aparezca explícitamente como firmante del mismo. Confirma, además, la temprana pulsión militante y el americanismo expansivo del reformismo: se presagia así la idea de una "hora americana".

Al grupo de temas que apuntan a la necesidad de reformar la propia vida universitaria, y que se reiterarán en varias publicaciones reformistas, se unirá una preocupación por la función social de la universidad y el conocimiento,

15 Pude consultar el texto del telegrama en el Museo Ricardo Rojas, Buenos Aires, Argentina. 
así como por el latinoamericanismo, que se anuncia ya en el "Manifiesto liminar". Como anota Gabriel del Mazo, éste "Fue publicado en Córdoba, el 21 de junio de 1918, en una edición extraordinaria de 'La Gaceta Universitaria', órgano de los estudiantes, y repartido profusamente en toda América, especialmente en las ciudades universitarias del país, Perú, Chile y Uruguay" ${ }^{16}$ Dicho documento se cierra con el grito emotivo de que "estamos viviendo una hora americana”, y anuncia "una verdadera revolución que ha de agrupar bien pronto bajo su bandera a todos los hombres libres del continente", ${ }^{17}$ tema que también encuentra eco en las publicaciones periódicas de la hora.

El "Manifiesto Liminar" representa el detonante escrito del movimiento de la Reforma Universitaria. Muy pocos días después se organiza ya un Congreso Estudiantil en la misma ciudad, en cuya clausura será el mismo Deodoro Roca (animador del movimiento y autor reconocido del manifiesto), quien lea el discurso dedicado a "La nueva generación americana", en julio de 1918. Las noticias de estos hechos se expandirán a través de las publicaciones de distintas partes del país y las propias redes universitarias difundirán las novedades invitando a las correspondientes iniciativas de adhesión y tomas de posición.

En el poderoso mensaje del "Manifiesto liminar" resuenan los ecos del "grito" estudiantil que había comenzado a extenderse desde meses atrás en dicha universidad, convertida a través del discurso de muchos reformistas en el último de los bastiones de la vieja concepción elitista, confesional, autoritaria, de la educación superior. ${ }^{18}$ En ese poderoso texto, que detona el "big bang" del movimiento, se reúnen a modo de masa crítica varias de las ideas, nociones epocales y sentires del reformismo, así como se anuncian las tensiones que habrán de desembocar en distintas posturas en torno al movimiento: exigencias de cambio en la vida universitaria; preocupación por replantear la relación entre universidad, sociedad e historia; voluntad americanista; religación con la tradición libertaria de Mayo de 1810 y papel heroico de la juventud, entre los principales.

Se trata de un texto breve y contundente, que en catorce párrafos, enmarcados por la invocación al destinatario en el primero de ellos ("La juventud argentina de Córdoba a los hombres libres de Sud América”) y el llama-

${ }^{16}$ Del Mazo, La Reforma Universitaria, 1918-1940, tomo I, p. 1.

17 “La juventud argentina de Córdoba a los hombres libres de Sud América”, en Del Mazo, t. I, pp. 1-3.

${ }^{18}$ Ana Clarisa Agüero ha sostenido en distintos trabajos que el exagerado carácter clerical y conservador atribuido a la Universidad de Córdoba es en buena medida un constructo ideológico de los reformistas. Véase por ejemplo, Agüero, “Del tiempo y la ciudad, Córdoba, 1918 y la Reforma Universitaria”, pp. 71-104. 
miento a las juventudes de América en el último ("La juventud universitaria de Córdoba, por intermedio de su federación, saluda a los compañeros de la América toda y les incita a colaborar en la obra de libertad que inicia”), desenvuelve, con la vehemencia de todo manifiesto, varios ejes: 1) Americanismo, 2) Lineamientos político-morales de la demanda estudiantil, 3) Relación entre el estudiantado y la sociedad, 4) Concepción de la educación, 5) Llamado a la juventud. ${ }^{19}$ En opinión de Portantiero, este texto "aporta dos dimensiones que serán características de la Weltanschauung reformista: la concepción del demos universitario y la ubicación latinoamericana, continental, del movimiento cordobés”. ${ }^{20}$ De fuerte tono arielista y juvenilista, el manifiesto deja entrever también aquello que el propio Deodoro Roca llamará más adelante "el ideal de la personalidad, realizándose en el plano de una educación estético-humanista".

El "Manifiesto liminar" afirma y defiende en su contundencia una serie de tesis fuertes, a la vez que interpela y moviliza. Hay en él un marcado carácter de denuncia y toma de partido, que a la vez que conduce a declarar adhesión o desacuerdo, representa una invitación a la acción y al compromiso solemne de quienes se adhieran a ella. Según Marc Angenot: "Lo que parece caracterizar al manifiesto — político o literario- es justamente el carácter manifiesto de su estructuración demostrativa”. ${ }^{21}$

El comienzo es ya un diagnóstico eléctrico, una declaración encendida, una idea de redención y un estilo afirmativo y performativo: "Hombres de una república libre, acabamos de romper la última cadena que, en pleno siglo XX, nos ataba a la antigua dominación monárquica y monástica. Hemos resuelto llamar a todas las cosas por el nombre que tienen. Córdoba se redime... estamos pisando sobre una revolución, estamos viviendo una hora americana". ${ }^{22}$

El llamamiento a una Córdoba libre reaparece aquí: "La rebeldía estalla ahora en Córdoba...”. Sigue la denuncia de la situación de las universidades, "refugio secular de los mediocres [...] fiel reflejo de estas sociedades decadentes [...] inmovilidad senil". Se refiere también al "anacronismo" de la

19 Arlotti, "El Manifiesto Liminar del 21 de junio de 1918: Texto Clave del Movimiento Reformista”, http://www.derecho.uba.ar/publicaciones/libros/pdf/la-reforma-universitariade-1918-y-sus-antecedentes/el-manifiesto-liminar-del-21-de-junio-de-1918.pdf, [consultado el 9 de julio de 2019].

20 Portantiero, Estudiantes y política en América Latina. El proceso de la Reforma Universitaria (1918-1938), p. 44.

21 Angenot, La parole pamphlétaire, p. 38. La traducción es mía.

22 Esta cita y las siguientes provienen de "La juventud argentina de Córdoba a los hombres libres de Sudamérica. Manifiesto de la Federación Universitaria de Córdoba”, reproducido en Del Mazo, La Reforma Universitaria, tomo I, pp. 1-5. 
universidad, su "alejamiento olímpico" del mundo, el autoritarismo de un profesorado que se cree nombrado por derecho divino. Términos que contrastan con la idea de juventud, rebeldía, cambio.

Se critica la falta de una relación sana entre el que enseña y el que aprende; la situación de la universidad se asocia más a la de una institución autoritaria apuntalada por reglamentos, estatutos y regímenes cuartelarios que por el amor de la enseñanza: "Las almas de los jóvenes deben ser movidas por fuerzas espirituales”. Autoridad contra magisterio, tradición contra ciencia, escucha de la verdad, experimentación. Cerrazón versus apertura, pasado versus presente y futuro: la herencia de lo arcaico, de la barbarie, autoridad, tiranía, falsedad, mal, descomposición, espíritu de casta, mediocridad e intereses creados son términos que se oponen al programa de renovación, en consonancia con el "derecho sagrado a la insurrección" y el "destino heroico de la juventud": "El sacrificio es nuestro mejor estímulo; la redención espiritual de las juventudes americanas nuestra única recompensa, pues sabemos que nuestras verdades lo son - y dolorosas- de todo el continente".

Vemos entonces cómo se va dando un "nudo" básico de ideas cuyas hiladas habrán de irse retomando y recombinando una y otra vez en textos posteriores: americanismo, juventud, heroísmo, ruptura con el pasado autoritario, desinterés y pureza, elección de los verdaderos maestros, ya que "sólo podrán ser maestros en la futura república universitaria los verdaderos constructores de almas, los creadores de verdad, de belleza y de bien”. He aquí la tríada de virtudes platónicas que tanto han repetido Rodó, los arielistas, los ateneístas (Henríquez Ureña, Vasconcelos, Reyes), y que alimentan "los ideales y principios que mueven a la juventud en esta hora única de su vida”.

Se contempla el nacimiento de "una verdadera revolución que ha de agrupar bien pronto bajo su bandera a todos los hombres libres del continente", y con ello se refuerza el horizonte americano al que aspira el movimiento.

El programa futuro y el sentido ético y humanista de la propuesta se opone a "La miseria moral, la simulación y el engaño a que pretendía filtrarse con las apariencias de la legalidad", al fariseísmo e "indigencia de ideales”, "regresión, ignorancia, vicio”. De manera hiperbólica se afirma que "A la burla respondimos con la revolución”: "La sanción moral es nuestra. El derecho también. Aquellos pudieron obtener la sanción jurídica, empotrarse en la ley...”. Hay entonces un planteo hondamente jurídico: enjuiciar las viejas normas desde los nuevos reclamos.

"Los métodos docentes estaban viciados de un estrecho dogmatismo, contribuyendo a mantener a la Universidad apartada de la ciencia y de las disciplinas modernas": se habla así de repetición, rutina, sumisión, dogma, clausura, conspiración contra la ciencia, tiranía de una secta religiosa, intereses egoístas. "A ellos se nos quiere sacrificar”. 
Tras este diagnóstico crudo se desemboca en una gran invitación: "Recojamos la lección, compañeros de toda América; acaso tenga el sentido de un presagio glorioso, la virtud de un llamamiento a la lucha suprema por la libertad”. Los americanos son así, para decirlo con palabras de Ingenieros, la "reserva moral” que permitirá la transformación.

Contra la perspectiva recalcitrante, "tiránica, obcecada”, que ve "en cada pensamiento una semilla de rebelión", se propone un gran programa de acción: "La juventud ya no pide. Exige [...]. Está cansada de soportar a los tiranos. Si ha sido capaz de realizar una revolución en las conciencias, no puede desconocérsele la capacidad de intervenir en el gobierno de su propia casa”.

Para profundizar en la intención significativa de este "Manifiesto" debemos recordar que no se trata de un texto aislado, sino que es sólo la punta de un iceberg, ya que se vio precedido y acompañado por innumerables acontecimientos, gestos simbólicos, prácticas, así como por impresos de diverso formato que daban cuenta de ellos, ligados a los movimientos previos y la toma de la Universidad por los estudiantes, como la clausura del internado en el Hospital de Clínicas, que se extendió a todo el sistema universitario, y la serie de actividades de protesta que fueron alimentando el brote del movimiento. Y a su vez el "Manifiesto" nombra, resume, reanuda, en un mismo texto todas estas hiladas, que a su vez abre a un proyecto intelectual futuro. De allí que insistamos en que es necesario atender al modo en que se entretejen las redes intelectuales y las redes textuales. Los textos se reprodujeron en formatos sencillos y económicos que ayudaban a su difusión, y las noticias y reflexiones se multiplicaron gracias al tendido de redes de gacetas, periódicos, revistas estudiantiles, en que se iban retomando los distintos asuntos. También tuvieron importancia las actas de las reuniones, reproducidas en los respectivos boletines de las federaciones universitarias.

Ya desde fines de 1917 se habían manifestado fuertes signos de agitación estudiantil. En la revista Cultura, animada por los alumnos de derecho de Córdoba, se publica la siguiente noticia: "Ya empiezan a manifestarse los primeros síntomas de un gran movimiento que tiene que venir fatalmente. $\mathrm{La}$ juventud no está enferma [...], mañana, tenemos derecho a esperarlo, será la juventud en masa la que se rebelará heroicamente contra la injusticia y la mentira". En otro texto leemos que "Ya empieza a sentirse, pues, ya la voz tan deseada, del aliento y de la esperanza, que todos cobijamos en lo más hondo de nuestros corazones. Esperemos con amor en esa juventud que hasta ayer callaba y la vida misma ha de darnos razón de su silencio”. 23

23 Fragmentos citados por Del Mazo, op. cit., tomo I, p. 468. 


\section{CONSTELACIÓN DE CONSTELACIONES}

Llamativamente rico y plural es el panorama que ofrecen las publicaciones del Reformismo, tanto las propiamente dichas como las que de algún modo configuran sus antecedentes o sus derivas. Si se toma en cuenta que a su vez las revistas, los boletines, hojas sueltas y documentos se fueron organizando en constelaciones conforme a los distintos momentos, los distintos lugares, los distintos grupos y propósitos, es posible pensar en familias dinámicas y cambiantes, impulsadas por diferencias, pero también notablemente atravesadas por recurrencias que hacen posible rastrear ciertas constantes en el ideario reformista.

Una posibilidad de clasificación es la que propone Natalia Bustelo en su "Bitácora de la Reforma Universitaria", que incluye una propuesta de asignación de estas revistas a cuatro grandes rubros. ${ }^{24}$ Retomo esta propuesta de clasificación porque nos permite tener un amplio panorama de la riqueza y diversidad de este tipo de publicaciones periódicas.

En primer lugar existen publicaciones que la estudiosa agrupa bajo el rótulo de "gremiales", ya que hacen prioritariamente a la defensa de los intereses de distintos sectores de la vida universitaria. Así, por ejemplo, los alumnos de medicina editarán revistas como El Estudiante Libre. Órgano de la Asociación de Estudiantes de Medicina (Montevideo, 1919-1956), El Fórceps. Periódico Universitario editado por Estudiantes de Medicina (La Plata, 1925-1926); La Cureta. Órgano de la Agrupación de Estudiantes de Medicina "Pro Reformas" (Buenos Aires, 1918-1926). Por su parte, los estudiantes de abogacía publicarán Themis. Órgano del Centro de Estudiantes de Derecho y Ciencias Sociales (Buenos Aires, 1918-1919). Sin embargo, si pensamos por ejemplo en La Cureta, veremos que ellas irán revistiendo un muy diferente y hasta discordante signo ideológico.

Habrá también diversos boletines, gacetas o publicaciones consideradas "órganos" de difusión de las ideas entre distintas federaciones universitarias y asociaciones estudiantiles, como el Boletín de la Federación Universitaria Argentina (Buenos Aires, 1920-1922), el Boletín de la Federación Universitaria de Buenos Aires (Buenos Aires, 1917-1918), Evolución. Órgano de la Asociación de los Estudiantes del Uruguay (Montevideo, 1908-1917), Juventud. Órgano de la Federación de Estudiantes de Chile (Santiago, 19111920), Verbum. Órgano del Centro de Estudiantes de la Facultad de Filosofía y Letras de Buenos Aires (Buenos Aires, 1912-1948) o Germinal. Órgano de la Asociación de Estudiantes de la Escuela Nacional de Comercio 
(Rosario, 1922-1923). Por las fechas en que surgen se hace evidente que datan de años anteriores al estallido reformista. El más antiguo es quizás El Estudiante. Semanario de literatura y variedades redactado por jóvenes estudiantes (Buenos Aires, 1872). Y desde luego que en el mero parteaguas de 1918 asistimos a la aparición de La Gaceta Universitaria. Órgano de la Federación Universitaria de Córdoba (Córdoba, 1918-1921).

Si bien muchas de ellas tuvieron una corta duración, una circulación no siempre amplia y una factura precaria, no dejaron de lograr un efecto poderoso al nuclear grupos y reforzar ideas e identidades: tuve varias en mis manos en el CeDInCI y otros archivos y bibliotecas, logré revisar e incluso fotografiar algunas de ellas, y pude apreciar cómo eran apoyadas a través de anuncios provenientes de egresados del propio gremio (consultorios médicos, odontológicos, bufetes de abogados, notarías), así como también por propagandas de librerías, editoriales, casas de encuadernación, casas de venta de trajes, uniformes, sombreros, relojes, pianos, cafeterías, cigarrillos... Hay también anuncios "cruzados": Repertorio Americano, por ejemplo, menciona su catálogo en algunas de ellas, y hay curiosos anuncios, como el de la compañía cinematográfica "Ariel” en el Boletín de la FUA, trimestral, año 1, núm. 1, de 1920.

Existieron también aquellas publicaciones que Bustelo agrupa como "culturales", y en ellas es notable la recurrencia de ciertos títulos, de ciertas figuras, que generan y permiten atraer a su vez constelaciones de sentido, inscribiendo las demandas estudiantiles coyunturales en el largo plazo de la reflexión. Empecemos por el nombre de Ariel, que no sólo se dará en distintos tipos de publicaciones sino en asociaciones y centros culturales de varios puntos de América (como el grupo Ariel de Montevideo que en su momento recibirá a Haya de la Torre). La expansión del arielismo ha sido sorprendente. Recordemos que ya en 1901, de acuerdo a Isabel de León, la Revista Literaria de República Dominicana comenzó a publicar por entregas el Ariel. Con ello desde luego se refuerza la presencia de la prédica y la obra de Rodó en los jóvenes inquietos de la hora, y se perfila un nuevo modelo ideal de la figura del maestro considerado una guía espiritual respetada y escuchada por los estudiantes. Recordemos que el Ariel se habrá de publicar más tarde en México, por parte de Bernardo Reyes a instancias de Pedro Henríquez Ureña y el joven Alfonso, y que Porfirio Parra la hará leer en voz alta y publicar en el boletín de la Escuela Nacional Preparatoria. Otras revistas apelaban a la figura de Atenea, que nos recuerda el peso que tuvo también la recuperación de la herencia griega para los ateneístas mexicanos. Otras llevan ya en el subtítulo una declaración programática: Inicial. Revista de la nueva generación (Buenos Aires 1923-1928) o la fundamental Valoraciones. Humanidades, crítica y polémica (La Plata, 1923-1928). Otra impor- 
tante familia de revistas llevará el título de Claridad, eco de la Clarté francesa fundada por Anatole France y Henri Barbusse.

Por fin, existiría otro grupo integrado por las que Bustelo denomina " $\mathrm{Pu}-$ blicaciones políticas internacionalistas”, y en el que reaparecen estos títulos que evocan nombres de tanta fuerza como Ariel (Montevideo, 1919-1931), Bases (Buenos Aires, 1919-1920), Claridad (Santiago de Chile, 1920-1923) Insurrexit (Buenos Aires, 1920-1921), Juventud (La Habana, 1923-1925), Mente (Córdoba, 1920), Prometeo (Buenos Aires, 1919), Verbo Libre (Rosario, 1920), entre otras.

La clasificación se cierra con las que la misma autora denomina "Publicaciones políticas latinoamericanistas", entre las que se cuentan, además de nombres como 1918, Acción Universitaria y Córdoba, las grandes presencias de Amauta (Lima, 1926-1930), Claridad (Lima, 1923-1924), Cultura (Montevideo, 1924-1926) y Renovación. Boletín mensual de ideas, libros y revistas de la América Latina (Buenos Aires, 1923-1930).

Todas ellas permitieron hacer circular noticias, documentos y tomas de posición ligados al reformismo, al papel de las nuevas generaciones y al latinoamericanismo. Contribuyeron también a consolidar una cierta retórica reformista, retroalimentando con artículos los sentidos de la oratoria estudiantil. Permitieron al mismo tiempo identificar, desarrollar, recombinar, someter a "condiciones de laboratorio", es decir, experimentar, poner en diálogo, invitar al debate y a las tomas de posición en torno a ciertas ideas, como lo veremos en un instante a partir del desarrollo del "juvenilismo". Ayudaron también a ir tejiendo un mapa simbólico de la América Latina desde el reformismo, tal como queda representado en la constelación que une a distintas ciudades de América (ya que el reformismo fue notoriamente urbano). Es decir, las revistas contribuyeron a abrir espacios, establecer mapas y cartografías, multiplicar el alcance de las ideas y consolidar formas de solidaridad lectora. ${ }^{25}$

Las revistas permitieron también establecer una base común en cuanto a valores y estructuras de sentimiento de la hora. Y desde luego que propiciaron la lectura, el comentario, la traducción y el homenaje de ciertos autores y obras faro, como es el caso de Rodó, Ingenieros, Ugarte, Korn, Palacios, Vasconcelos, Henríquez Ureña, entre los maestros de la juventud, y pensadores y escritores como Romain Rolland. Pensemos que, además del Ariel y Motivos de Proteo, fue decisiva para toda esta generación la lectura de $E l$

25 Excelente ejemplo de estos procesos ha sido el Boletín Renovación, como lo muestra el estudio de Pita González, La Unión Latino Americana y el Boletín Renovación. Redes intelectuales y revistas culturales en la década de 1920. 
hombre mediocre de José Ingenieros. Hubo también autores europeos de gran importancia: pensadores como Boutroux, Nietzsche, Bergson y escritores como Verhaeren o Rolland. A este último (quien por cierto llegó a cartearse con Haya de la Torre y Vasconcelos) se dedicaron números de homenaje en distintas publicaciones.

Insistamos en el valor estratégico que puede alcanzar la generación de una tradición de lecturas en común, y que a su vez sirve para dar mayor fuerza y densidad a la génesis de un nuevo sector que, como el estudiantil, buscaba perfilarse como un nuevo actor social.

Los boletines, diarios y revistas fueron también espacios simbólicos para generar, consolidar y cargar de sentido las distintas posturas estudiantiles en esa difícil tensión entre dejar que el reclamo estudiantil se ciñera a la vida universitaria y procurar acercarse a grupos y tendencias políticas como el socialismo o el bolchevismo, a la vez que tomar distancia de otros, como las posturas nacionalistas extremas que se estaban dando, por ejemplo, en la Argentina o en Chile. En efecto, no se debe olvidar que existieron además posturas de derecha y nacionalistas defendidas por algunos sectores estudiantiles que se consideraban también a sí mismos reformistas e intentaron reinterpretar desde su particular signo ideológico este amplio y complejo movimiento.

De este modo, no resulta tan sencillo separar las publicaciones y lecturas en compartimentos estancos como "antecedentes", "textos protagónicos" o "consecuencias", ni intentar deslindar la militancia estudiantil de la militancia política, los actores de los autores, ya que los hilos en muchos casos atraviesan las distintas etapas, y las ideas componentes de esas estructuras de sentimiento se recombinan para dar lugar a nuevas síntesis y generar un "nosotros” que se redefine dinámicamente al oponerse a las diferentes construcciones de sus antagonistas.

El artículo reciente de Natalia Bustelo y Lucas Domínguez Rubio, "Radicalizar la Reforma Universitaria. La fracción revolucionaria del movimiento estudiantil argentino, 1918-1922" es un ejemplo de singular valor en cuanto muestra cómo los avances en el relevamiento y análisis de fuentes van a su vez permitiendo abrir nuevas interpretaciones. Este estudio llama nuestra atención al mostrar la franca intervención que se dio en los primeros años (1918-1922) por parte de una franja de agrupaciones y publicaciones reformistas argentinas para vincularse a la oleada revolucionaria internacional "inaugurada por Rusia y con ello a las izquierdas bolcheviques locales", demostrando así, a diferencia de las tesis por mucho tiempo preponderantes, que no necesariamente estos sectores sostuvieran una postura moderada". ${ }^{26}$

26 Bustelo y Domínguez Rubio, "Radicalizar la Reforma Universitaria. La fracción revolucionaria del movimiento estudiantil argentino, 1918-1922”, p. 31. 
Este artículo constituye un valioso aporte para comprender las tensiones entre las distintas tendencias políticas que se fueron poniendo en evidencia a través de distintas revistas, entre las que se encontraban Bases (Buenos Aires, 1919-1920), Clarín (Buenos Aires, 1919-1920), Insurrexit (Buenos Aires, 1920-1921), Mente (Córdoba, 1920), Alborada (La Plata, 1920-1921), Verbo Libre (Rosario, 1920-1921), La Antorcha (Rosario, 1921-1923), Germinal (Rosario, 1922-1923) y Germinal (La Plata, 1919-1920), entre otras. A partir de la lectura de este artículo queda claro que el sector estudiantil buscó reafirmar, a través de la letra impresa, un nuevo lugar como actor político, a la vez que se fueron definiendo distintas posiciones ideológicas y militantes en respuesta a los acontecimientos internacionales (la Gran Guerra, la Revolución Rusa, por ejemplo) y nacionales (protestas y huelgas de trabajadores), que hicieron que, mientras algunas revistas se mantuvieron más ligadas al americanismo, al arielismo, al idealismo y al juvenilismo, otras se volcaran al antiimperialismo y a distintas posiciones del anarquismo y el bolchevismo. Sólo un cuidadoso seguimiento de los textos y programas de las diferentes publicaciones como la que llevaron a cabo ambos investigadores permitirá a su vez descubrir nuevas tramas y redes distintivas.

\section{JUVENTUD, ENTUSIASMO, ENERGÍA}

Es notable la temprana toma de conciencia que tuvieron los reformistas de su propia personería y de su propio "perfil", y la permanente exigencia de hacer balances, valoraciones y sumas sigue para complacencia de muchos que fueron gestando valores de identificación, y para queja de unos cuantos también. Fue un movimiento que propició ampliamente la reflexión, la valoración, el debate sobre su propio sentido. Y no es casual que muy tempranamente también uno de sus protagonistas, Gabriel del Mazo, generara varios tomos donde se recogen documentos, proclamas y valoraciones. El reformismo reavivó el sentido de la palabra impresa, y también intentó desde el inicio entrar en diálogo con la historia: una historia en la que los propios reformistas ingresaron con conciencia de protagonismo, definiendo su lugar y el de sus maestros y guías, en una nueva tensión entre su necesidad de fundar nuevas tradiciones y su exigencia urgente de presente y de futuro.

La frecuente "migración" de textos y vectores de ideas entre libros, revistas y periódicos también es llamativa. Tomemos como ejemplo el texto de José Ingenieros, "Juventud, entusiasmo, energía", publicado en la revista porteña Babel, ${ }^{27}$ como adelanto editorial de esa serie de máximas morales 
combinadas en "trípticos" que más tarde se publicarán conjuntamente bajo el título de Las fuerzas morales (1926), que retoma, compendia, reinterpreta, recombina con otros sentidos y símbolos, y permite difundir a través de esta publicación el sentido del juvenilismo, a la vez que confirmar el lugar que el reformismo otorgó a sus "maestros". Representación escrita del gesto por el que el guía de juventudes se dirige a sus seguidores, este ejemplo permite advertir cómo ciertas revistas que no se han clasificado como francamente "reformistas" pueden también incluir autores y textos ligados directa o indirectamente a su ideario.

A partir de un orden "didáctico", Ingenieros agrupa en tres secciones cada uno de los conceptos anunciados en el título. Organiza campos semánticos en que juventud-ideal-enstusiasmo-optimismo-renovación-porvenirgrandeza-moral- función social-proyecto de futuro se imantan conformando un grupo de ideas afines que se contraponen a las del campo integrado por términos como pasado, inmovilismo, mediocridad, falta de compromiso, etcétera. A la vez imprime un nuevo giro expansivo a sus reflexiones al dedicarlas a la juventud de América.

Ingenieros condensa así ideas y traduce en sus propios términos estructuras de sentimiento que son ya parte de toda una generación y permean el discurso social. Ingenieros pone nombre, da legibilidad y visibilidad a ciertos valores ligados a la juventud, la energía y la posibilidad de transformación a la vez que confirma la relación maestro-alumno (un simbolismo que es también el del arielismo) y que se contrapondrá críticamente al viejo esquema jerárquico de la universidad tradicional. Sus palabras contribuyen a su vez a fortalecer su imagen como maestro de la juventud. Dice allí:

Aprendiendo a pensar se evita el desperdicio de la propia energía; el fracaso es debido a simple ignorancia de las causas que lo determinan. Para hacer bien las cosas, hay que pensarlas certeramente [...]. Los hombres sin energía carecen de personalidad social y no cooperan en cosa alguna de provecho [...]. porque no han sabido pensar que la eficacia de la energía finca en la cultura y en los ideales. La apatía del indolente y el fracaso de los agitados se incuban en la rutina y en la ignorancia. La incapacidad de prever y de soñar es el obstáculo que obstruye la expansión de la personalidad. Educando la energía, enseñando a mirarla, se plasmaron los nuevos destinos de los pueblos [...]. Los jóvenes que no saben mirar hacia el porvenir y trabajan para él, son miserables lacayos del pasado y viven asfixiándose entre sus escombros [...] a la juventud están confiadas las esperanzas de los que aman la libertad y la justicia. Pensando en una humanidad mejor, pueden los jóvenes aumentar la parte de felicidad común y disminuir el lote de comunes sufrimientos...

Juventud, pensamiento, energía, porvenir, esperanzas, ideales, constituyen en voz del maestro los grandes motores de cambio y se oponen al lastre 
de los preconceptos viejos y de aquellos sujetos que sólo pueden mirar hacia el pasado. Las ideas se combinan con otras: nueva conciencia moral, juventud de nuestra América, en un crescendo optimista que le permite anunciar en un tono profético a la vez que laico y racionalista los tiempos de "renovación”:

La hora es palingenesia y un halo de amanecer nimba la cabeza de la juventud [...] una sola generación pensante y actuante basta para dar a un pueblo personalidad en el mundo, creando una nueva conciencia moral, plasmando originales formas de arte, agregando verdades al servicio de las ciencias, inspirando la vida común y generosos preceptos de solidaridad. Florezcan en la juventud de nuestra América sus nuevos anhelos que templen el corazón y lo hacen latir por ideales que son anticipaciones inteligentes en la historia de la humanidad. El ritmo de los tiempos nuevos [...], anuncios de integral renovación de las instituciones que favorecerá una selección más ajustada a la naturaleza. Los pueblos del porvenir serán algo más que los estados políticos del pasado [...]. Pongamos alas a los jóvenes.

\section{A MODO DE CONCLUSIÓN}

Interesante es así ver cómo las ideas del Reformismo "permearon” y se "cruzaron" con otras publicaciones de alcance local, nacional, latinoamericanista: preocupaciones que surgieron a partir de distintos centros de educación superior pronto lograron expandir su prédica a otras revistas de presencia nacional y latinoamericana: Repertorio Americano, Nosotros, Amauta, Renovación, Cuadernos Americanos incluso, y aun otras publicaciones, abrevaron en las ideas y autores del reformismo y entraron en diálogo con muchos de sus postulados.

Revistas como Valoraciones fueron también testimonio del modo en que las redes reformistas permitieron trazar corredores para el tránsito de algunos representantes reunidos en el Primer Congreso Internacional de Estudiantes de México de 1921. En mi estancia del año 2018 en la biblioteca de la Universidad Popular Alejandro Korn de La Plata, Argentina, pude localizar artículos sueltos de revistas platenses donde se veía la presencia de Vasconcelos, Reyes, Henríquez Ureña, a la hora de presentar los alcances y los resultados de la Revolución Mexicana, en el campo de la cultura y las artes plásticas, y en particular el muralismo.

Por fin, no debemos olvidar el valor que tuvo la letra impresa para el movimiento reformista, y las mil y una anécdotas en torno al papel del libro y la revista como detonantes de la alfabetización, la educación y el cambio social. 
En efecto, el reformismo ha sido uno de los movimientos que más se apoyó en la letra impresa para configurarse, difundirse y articularse con la sociedad, al mismo tiempo que promovió de manera creciente una reflexión sobre sí mismo, sus alcances, su legado. Este proceso reflexivo fue acompañando y retroalimentando a su vez el proceso de expansión continental, facilitada esta última por cartas, encuentros, viajes, y nuevas dinámicas de sociabilidad, así como también por el admirable crecimiento de una miríada de manifestaciones de la letra impresa. De allí que propongamos que las redes intelectuales se retroalimentaron con las redes textuales.

Por otra parte, la Reforma Universitaria ha sido en verdad uno de los procesos cuyos distintos actores más enfáticamente trabajaron en su autorrepresentación intelectual —aun cuando no dejó de haber marcadas tensiones $\mathrm{y}$ aun contradicciones que fueron a su vez detonantes de diferencias y formación de nuevos grupos. Fue también uno de los movimientos que más señaladamente se estudió a sí mismo, y que a través de la determinación de una serie de elementos básicos, procuró encontrar un "común denominador" que comprendía demandas individuales, generacionales, sectoriales, sociales, ciudadanas, universales, y promovía un sentido americanista, logrando así expandir su mensaje hacia distintos puntos de nuestro continente, multiplicando a su vez esas redes intelectuales y redes textuales en recíproca alimentación, aunque al mismo tiempo la riqueza y complejidad de las demandas programáticas, sociales, políticas e ideológicas agudizaran diferencias y contradicciones al punto de generar nuevos sistemas de redes y constelaciones de textos que sólo muy recientemente, $\mathrm{y}$ gracias a la posibilidad inédita de trabajar con nuevas fuentes recuperadas, están recibiendo la atención que demandaban.

\section{BIBLIOGRAFÍA}

Agüero, Ana Clarisa, “Del tiempo y la ciudad. Córdoba, 1918 y la Reforma Universitaria”, Mario Albornoz y Manuel Crespo (comps.), La universidad reformada. Hacia el centenario de la Reforma Universitaria de 1918, Buenos Aires, Eudeba, 2017, pp. 71-104.

Angenot, Marc, La parole pamphlétaire, París, Payot, 1982.

Arlotti, Raúl, “El Manifiesto Liminar del 21 de junio de 1918: Texto Clave del Movimiento Reformista”, Facultad de Derecho, Universidad de Buenos Aires, http://www.derecho.uba.ar/publicaciones/libros/pdf/la-reforma-universitariade-1918-y-sus-antecedentes/el-manifiesto-liminar-del-21-de-junio-de1918.pdf, [consultado el 9 de julio de 2019].

Bergel, Martín, “América Latina, pero desde abajo: prácticas y representaciones intelectuales de un ciclo histórico latinoamericanista, 1898-1936”, Cuadernos 
de Historia, núm. 36, Santiago de Chile, 2012, pp. 7-36.

https://doi.org/10.4067/S0719-12432012000100001

Bergel, Martín (coord.), Los viajes latinoamericanos de la Reforma Universitaria, Rosario, Humanidades y Artes ediciones, 2018.

Bustelo, Natalia, Todo lo que necesitás saber sobre la Reforma Universitaria, Buenos Aires, Paidós, 2018. https://doi.org/10.4000/corpusarchivos.2246.

Bustelo, Natalia y Lucas Domínguez Rubio, "Radicalizar la Reforma Universitaria. La fracción revolucionaria del movimiento estudiantil argentino, 1918-1922”, Anuario Colombiano de Historia Social y de la Cultura, Bogotá, vol. 44, núm. 2, 2017, pp. 31-62. https://doi.org/10.15446/achsc.v44n2.64014.

Ciria, Alberto y Horacio Sanguinetti, La Reforma Universitaria (1918-2006), Santa Fe, Ediciones Universidad Nacional del Litoral, 2006 [1a. ed., 1968].

Cúneo, Dardo (comp.), La Reforma Universitaria (1918-1930), Caracas, Biblioteca Ayacucho, 1978.

Del Mazo, Gabriel, La Reforma Universitaria (1918-1940), La Plata, Edición del Centro [de] Estudiantes de Ingeniería, 1941. [I. El Movimiento Argentino; II. Propagación Americana; III. Ensayos Críticos].

Ingenieros, José, “Juventud, entusiasmo, energía”, Babel. Revista de Arte y Crítica, núm. 4, junio de 1921, pp. 1-3.

, “La Reforma Universitaria se extiende ya por toda América Latina” [1924], Gabriel del Mazo, La Reforma Universitaria (1918-1940), tomo III. Ensayos Críticos, La Plata, Edición del Centro [de] Estudiantes de Ingeniería, 1941, pp. 115-118.

Julliard, Jacques, "Le monde de revues au début du siècle. Introduction”, Les revues dans la vie intellectuelle 1885-1914, Cahiers Georges Sorel, París, núm. 5, 1987, pp. 3-9. https://doi.org/10.3406/mcm.1987.940.

"La juventud argentina de Córdoba a los hombres libres de Sud América. Manifiesto de la Federación Universitaria de Córdoba” [1918], Gabriel del Mazo, La Reforma Universitaria (1918-1940), tomo I. El Movimiento Argentino, La Plata, Edición del Centro [de] Estudiantes de Ingeniería, 1941, pp. 1-5.

Lozares Colina, Carlos et al., "Relaciones, redes y discurso: revisión y propuesta en torno al análisis reticular de datos textuales”, Redes. Revista Hispana para el Análisis de Redes Sociales, Barcelona, vol. 1, núm. 1, 2002. https://doi.org/10.5565/rev/redes.486.

Merleau-Ponty, Maurice, "Sur la phénoménologie du langage” [1951], Éloge de la Philosophie et autres essais, París, Gallimard, 2016, pp. 73-95.

Petra, Adriana, Intelectuales y Cultura Comunista. Itinerarios, problemas y debates en la Argentina de posguerra, Buenos Aires, Fondo de Cultura Económica, 2017.

Pita González, Alexandra y Carlos Marichal, Pensar el antiimperialismo, ensayos de historia intelectual, México, El Colegio de México-Universidad de Colima, 2012. 
Pita González, Alexandra, La Unión Latino Americana y el Boletín Renovación. Redes Intelectuales y revistas culturales en la década de 1920, México, El Colegio de México-Universidad de Colima, 2009.

Portantiero, Juan Carlos, Estudiantes y política en América Latina. El proceso de la Reforma Universitaria (1918-1938), México, Siglo Veintiuno editores, 1978.

Roca, Deodoro, “La nueva generación americana”, Hugo O. Andrade y Leonardo Rabinovich (comps.), Textos universitarios escogidos. Homenaje de la Universidad Nacional de Moreno a 100 años de la Reforma Universitaria, Moreno, UNM Editora, 2018, pp. 50-56.

Tarcus, Horacio, "Revistas, intelectuales y formaciones culturales izquierdistas en la Argentina de los veinte”, Revista Iberoamericana, vol. 70, núms. 208-209, 2004, pp. 749-772. https://doi.org/10.5195/REVIBEROAMER.2004.5508.

Tünnermann Bernheim, Carlos, "La reforma universitaria de Córdoba”, Educación Superior y Sociedad, vol. 9, núm. 1, 1998, pp. 103-127.

Weinberg, Gregorio, "La reforma universitaria”, Sarmiento, Bello, Mariátegui y otros ensayos, Buenos Aires, Academia Nacional de Educación, 1999, pp. 141-164.

Acervos digitales

“AméricaLee, Portal de Revistas Latinoamericanas del siglo Xx del Centro de Documentación e Investigación de la Cultura de Izquierdas (CeDInCI)”, Buenos Aires, http://americalee.cedinci.org/. 